\title{
Quality of life in the elderly: Psychometric properties of the WHOQOL-OLD module in Mexico
}

\author{
Ana Luisa González-Celis ${ }^{1 *}$, Juana Gómez-Benito ${ }^{2,3}$ \\ ${ }^{1}$ Division of Research and Graduate Studies, Faculty of Higher Education Iztacala, National Autonomous University of Mexico, \\ Mexico City, Mexico; ${ }^{*}$ Corresponding Author: algcr10@,hotmail.com \\ ${ }^{2}$ Department of Behavioral Sciences Methodology, Faculty of Psychology, University of Barcelona, Barcelona, Spain \\ ${ }^{3}$ Institute for Brain, Cognition and Behaviour (IR3C), University of Barcelona, Barcelona, Spain
}

Received 31 October 2013; revised 28 November 2013; accepted 8 December 2013

Copyright (C) 2013 Ana Luisa González-Celis, Juana Gómez-Benito. This is an open access article distributed under the Creative Commons Attribution License, which permits unrestricted use, distribution, and reproduction in any medium, provided the original work is properly cited.

\section{ABSTRACT}

The purpose was to examine and compare the psychometric properties of a Mexican Spanish version of the WHOQOL-OLD module. The instrument was applied to 285 individuals aged over 60 years $($ mean $=69.26$, SD $=6.52$ ). All participants completed a demographic data sheet, the WHOQOL-OLD, the Beck Depression Inventory (BDI), and the Geriatric Depression Scale (GDS); 182 of the 285 participants also completed a quality of life questionnaire for diabetic patients (DQOL). Acceptable levels of reliability were found, with Cronbach's alpha values between $\mathbf{0 . 7 0}$ and $\mathbf{0 . 9 0}$ for overall quality of life and all domains except for autonomy, where the alpha value was low. The exploratory factor analysis carried out to examine the construct validity of the instrument yielded six domains: sensory abilities, autonomy, past/present/future activities, social participation, death and dying, and intimacy (explained variance of $62.95 \%$ ). The mean overall quality of life score was $\mathbf{9 4 . 8 6}$ ( $S D=13.68$, range 50 to 120 ). The WHOQOL-OLD module showed criterion validity and concurrent validity with respect to the $B D I(r=-0.516, p=$ $0.034)$, the GDS $(r=-0.336, p=0.002)$, and the DQOL $(n=182, r=0.159, p=0.032)$. Discriminant validity was also confirmed with respect to selfperceived health $(t=2.701$, d.f. $=225, p=0.007)$ and education $\left(F_{(3,280)}=9.015, p<0.001\right)$, for both overall quality of life and some of its dimensions, but this was not the case with respect to gender $(t=1.292$, d.f. $=283, p>0.05)$. We conclude that the Mexican Spanish version of the WHOQOL-OLD module has adequate psy- chometric properties.

Keywords: Quality of Life; Elderly; WHOQOL-OLD; Psychometric Properties; Mexico

\section{INTRODUCTION}

The proportion of people aged 60 and over worldwide is growing faster than any other age group. Between 1970 and 2025, an increase in the number of older persons of some 694 million (or 223\%) is expected. Indeed, it is estimated that by 2025 there will be around 1.2 billion people over the age of 60 , while by 2050 there will be 2 billion, with 80 percent of them living in developing countries [1].

In addition to investigating and determining the pace of the population's aging, there is also a need to study the quality of aging and, subsequently, to design interventions that can promote a healthy aging process. Consequently, researchers in geriatrics are increasingly interested in identifying the factors which are relevant to the quality of life in older adults $[2,3]$

The WHO Quality of Life Group has recently developed the WHOQOL-OLD module [4]. Through a simultaneous transcultural methodology, this instrument is designed to be suitable for cross-cultural comparisons. Furthermore, alongside the WHOQOL-100 [5] and the WHOQOL-BREF [6,7], it constitutes a useful alternative tool for investigating quality of life in older adults, not least as it includes relevant aspects that are not covered by instruments originally designed for non-elderly populations.

Power et al. [4], representing the WHOQOL group, emphasize that due to the specificities shown by the older adult population in the different centers involved in 
international data collection, there is a need to develop quality of life measurement tools directed toward older adults, and to test these instruments in a transcultural context.

The aim of the present study was to evaluate the psychometric properties of a Mexican Spanish version of the WHOQOL-OLD module, specifically by analyzing its internal consistency, construct validity, criterion validity, concurrent validity and discriminant validity.

\section{METHOD}

\subsection{Participants}

The sample comprised 285 elderly people aged between 60 and 98 years $($ mean $=69.26, \mathrm{SD}=6.52 ; 193$ women, 92 men). They were recruited through health centers or recreational day centers in two states of Mexico, as well as in the capital, Mexico City. Their socioeconomic status was lower middle class, and the majority had only a basic level of education. Regarding marital status, $56 \%$ were married or had a partner, $29 \%$ were widowed, and $15 \%$ were single, divorced, or separated.

\subsection{Measures}

Socio-demographic data. The socio-demographic information sheet included questions about gender, age, educational level, marital status, and self-perceived health status.

WHOQOL-OLD. The WHOQOL-OLD is a 24-item self-report instrument that is divided into six domains: Sensory Abilities (SA); Autonomy (A); Past, Present, and Future Activities (PPFA); Social Participation (SP); Death and Dying (DD); and Intimacy (I) (4 items per subscale). Each domain provides an individual score, and an overall score is also calculated from the set of 24 items. Answers are based on a 5-point Likert response scale, with items $1,2,6,7,8,9,10$ being reverse scored. Although all the response scales have five points they vary in their anchors: "Not at all"/"An extreme amount"; "Completely"/“Extremely"; "Very poor"/"Very good”; "Very dissatisfied"/"Very satisfied"; "Very unhappy/Very happy"). The Spanish version of the scale [8] was adapted to colloquial features of Mexican Spanish. Total scores on the WHOQOL-OLD range from 24 to 120 , with higher scores being indicative of better quality of life (QoL).

Beck Depression Inventory (BDI) [9]. This instrument assesses the presence and level of depressive symptoms and when validated in a Mexican population [10] it proved suitable for studying clinical and non-clinical populations. Scores range from 0 to 63 , with higher scores indicating greater severity of depressive symptoms.

Geriatric Depression Scale. The 15-item version of the Geriatric Depression Scale (GDS) [11] has previ- ously been adapted for Mexican older adults by González-Celis \& Sánchez-Sosa [12]. Possible total scores range from 0 to 15 , and a score of 5 or more indicates the presence of depressive symptoms.

Diabetes Quality of Life (DQOL). The DQOL measure [13] was developed for both type 1 and type 2 diabetes. A Spanish version of the instrument was validated by Robles-García, Cortázar, Sánchez-Sosa, Páez-Agraz, and Nicolini-Sánchez [14], and it was subsequently adapted for older Mexican adults by Hattori [15]. Its 46 items measure four domains that are highly relevant to treatment perceptions: satisfaction with treatment, impact of treatment, worry about the future effects of diabetes, and worry about social/vocational issues. Items are scored on a 5-point Likert scale and are of two general formats. One format asks about the frequency of negative impact of diabetes itself or of the diabetes treatment (e.g., "How often do you worry about whether you will pass out?") and provides response options from 1 (all the time) to 5 (never). The second format asks about satisfaction with treatment and quality of life (e.g., "How satisfied are you with the time you spend exercising?") and is scored from 1 (very dissatisfied) to 5 (very satisfied). Higher scores on DQOL items and subscales are, therefore, positive and indicate the absence of problems and greater satisfaction.

\subsection{Procedure}

All participants $(\mathrm{N}=285)$ completed three instruments (WHOQOL-OLD, BDI, and GDS), as well as the sociodemographic data sheet. Only 182 patients completed the DQOL. Subjects were interviewed and answered the question "In general, do you consider yourself healthy or unhealthy?" On the basis of their response they were categorized as healthy or unhealthy, and this was taken as an indicator of self-perceived, rather than actual, health status. All participants were informed about the purposes of the study and were ensured that all data obtained would remain confidential. They all signed an informed consent form that was approved by the Research Ethics Committee of the university in which the study was carried out. Interviewers were psychology undergraduates who had previously received training in how to apply the various instruments used. Depending on the status of the participant, the instruments were self-administered, administered with the interviewer's help, or completely administered by the interviewer. In cases where the interviewer's participation was required, they were asked not to interfere with the subjects' understanding of the items and told not to rephrase or supply synonyms for the words used in the instrument items.

\subsection{Statistical Analysis}

The data obtained were examined by means of de- 
scriptive analysis and psychometric tests for reliability and validity (using IBM SPSS Statistics 19). Internal consistency was assessed on the basis of Cronbach's alpha (criteria of acceptability $0.70<0.90$ ), which tests the strength of the association between each scale item and the full scale. Factor analysis was used to examine the dimensionality of the questionnaire, with the following criteria being applied: the correlation matrix should include many coefficients of 0.30 and above; the Kaiser-Meyer-Olkin (KMO) index of sampling adequacy (KMO) [16,17] should exceed the threshold of 0.60 ; Bartlett's test of sphericity should be statistically significant at $p=0.001$ so as to support the factorability of the correlation matrix and to confirm that the use of factor analysis was appropriate [18]; and eigenvalues had to be greater than 1.0 in order to support the construct validity of the scale. Criterion validity and concurrent validity (convergent and divergent) were tested by assessing the strength of Pearson's r correlations between the scale and similar or relevant/dissimilar measures (WHOQOL-OLD with respect to the BDI, GDS, and DQOL). Discriminant validity was tested by means of the Student's $t$ test or ANOVA, examining the relationship between the WHOQOLOLD and each of its domains and socio- demographic variables (gender, educational level, and selfperceived health status). Statistical significance was set at $p<0.05$, and effect sizes were measured by means of Cohen's d [19].

\section{RESULTS}

Cronbach's alpha as a measure of internal consistency reached satisfactory values for each facet score (range from $\alpha=0.75$ to $\alpha=0.85)$ and also for the total score $(\alpha=$ 0.88) (Table 1). These alpha values are similar to those reported by the WHO Quality of Life Group.

The 24 items of the WHOQOL-OLD were subjected to principal components analysis (PCA), using SPSS, in order to examine the factor structure. The suitability of conducting a factor analysis with these data was first as-

Table 1. Cronbach's alpha values for the Mexican population and those reported by the WHOQOL-OLD Group.

\begin{tabular}{ccc}
\hline & $\begin{array}{c}\text { Mexico } \\
(\mathrm{N}=285)\end{array}$ & $\begin{array}{c}\text { WHOQOL-OLD } \\
\text { field trial sample } \\
(\mathrm{N}=5566)[4,8]\end{array}$ \\
\hline Sensory Abilities (SA) & 0.78 & 0.84 \\
Autonomy (A) & 0.56 & 0.72 \\
Past/Present/Future & 0.75 & 0.74 \\
Activities (PPFA) & 0.79 & 0.79 \\
Social Participation (SP) & 0.83 & 0.84 \\
Death and Dying (DD) & 0.85 & 0.88 \\
Intimacy (I) & 0.88 & 0.89 \\
Total Score (Overall) & & \\
\hline
\end{tabular}

sessed based on the aforementioned criteria, which revealed the following: many of the correlations in the correlation matrix were 0.30 or above; the KMO index of sampling adequacy was 0.85 , exceeding the recommended value of 0.60 [16,17]; and Bartlett's test of sphericity [18] was statistically significant (chi-square $2835.758,276$ degrees of freedom, $p<0.0001$ ), supporting the factorability of the correlation matrix. PCA revealed the presence of six components for which the eigenvalues exceeded 1, and together these explained $62.95 \%$ of the total variance in QoL between respondents: component 1 explained the largest proportion of the variance $(13.33 \%)$, this being supported by inspection of the scree plot [20]. Applying the Kaiser criterion of retaining all components with eigenvalues above 1 , most items $(\mathrm{n}=$ 21/24) loaded strongly $(0.4+)$ : on the first component three items loaded strongly $(0.4+)$ and one loaded moderately $(0.3+)$; four items loaded strongly $(0.4+)$ on each of the second, third, and fourth components; on the fifth component three items loaded strongly $(0.4+)$ and one loaded mildly $(0.2+)$; and on the sixth component, two items loaded strongly $(0.4+)$, one loaded mildly $(0.2+)$, and one item did not load, it loading instead on the fifth component (Table 2).

There is no gold standard QoL measure to assess criterion validity, but concurrent validity (convergent and discriminant) was tested here. The WHOQOL-OLD correlated positively with the DQOL $(\mathrm{r}=0.159, p<0.032)$, as would be expected, and negatively with both the BDI ( $\mathrm{r}=$ $-0.516, p<0.034)$ and the GDS $(r=-0.336, p<0.002)$. Participants reported optimum levels of QoL when DQOL was better (higher scores), and when BDI and GDS scores were low.

In terms of the discriminant validity of the WHOQOL-OLD, Tables 3-5 show comparisons of the quality of life scores (for each domain and total) obtained by different subgroups defined by self-perceived health status, educational level, and gender. Healthy participants scored higher than unhealthy participants on all domains of quality of life and, therefore, also on overall QoL. The effect size of these differences was medium in all cases except for Autonomy, Death and Dying, and Intimacy, where the effect was small (Table 3). With regard to educational level, the analysis showed that quality of life scores (both by domain and overall) increased in line with participants' level of education (Table 4).

Finally, the results for gender only revealed significant differences between men and women on the QoL scores for the domains SP and Death and Dying (Table 5).

\section{DISCUSSION}

Factor analysis supported the multidimensional structure of the Mexican Spanish version of the WHOQOLOLD module. However, more detailed examination of the 
Table 2. Rotated component matrix ${ }^{\mathrm{a}}$.

\begin{tabular}{|c|c|c|c|c|c|c|}
\hline \multirow{2}{*}{ Items } & \multicolumn{6}{|c|}{ Component } \\
\hline & 1 & 2 & 3 & 4 & 5 & 6 \\
\hline \multicolumn{7}{|l|}{ Social Participation } \\
\hline 18. Satisfied with opportunity to participate in community & 0.805 & & & & & \\
\hline 17. Satisfied with level of activity & 0.787 & & & & & \\
\hline 16. Satisfied with the way you use your time & 0.775 & & & & & \\
\hline 14. Have enough to do each day & 0.348 & & & & & \\
\hline \multicolumn{7}{|l|}{ Intimacy } \\
\hline 23. Opportunities to love & & 0.863 & & & & \\
\hline 24. Opportunities to be loved & & 0.856 & & & & \\
\hline 21. Feel a sense of companionship in life & & 0.735 & & & & \\
\hline 22. Experience love in your life & & 0.728 & & & & \\
\hline \multicolumn{7}{|l|}{ Death and Dying } \\
\hline 7. Afraid of not being able to control death & & & 0.863 & & & \\
\hline 6. Concerned about the way you will die & & & 0.830 & & & \\
\hline 8. Scared of dying & & & 0.811 & & & \\
\hline 9. Fear pain before death & & & 0.712 & & & \\
\hline \multicolumn{7}{|l|}{ Sensory Abilities } \\
\hline 2. Loss of sensory abilities affect participation in activities & & & & 0.849 & & \\
\hline 1. Impairments to senses affect daily life & & & & 0.838 & & \\
\hline 10. Problems with sensory functioning affect ability to interact & & & & 0.678 & & \\
\hline 20. Rate sensory functioning & & & & 0.515 & & \\
\hline \multicolumn{7}{|l|}{ Past, Present and Future Activities } \\
\hline 12. Satisfied with opportunities to continue achieving & & & & & 0.618 & \\
\hline 13. Received the recognition you deserve in life & & & & & 0.443 & \\
\hline 19. Happy with things to look forward to & & & & & 0.438 & \\
\hline 15. Satisfied with what you've achieved in life & & & & & 0.277 & \\
\hline \multicolumn{7}{|l|}{ Autonomy } \\
\hline 5. People around you are respectful of your freedom & & & & & & 0.738 \\
\hline 3. Freedom to make own decisions & & & & & & 0.714 \\
\hline 4. Feel in control of your future & & & & & & 0.286 \\
\hline 11. Able to do things you'd like & & & & & 0.716 & \\
\hline$\%$ of Variance Explained & 13.328 & 11.996 & 11.537 & 9.977 & 9.959 & 6.152 \\
\hline Cumulative $\%$ of Variance Explained & 13.328 & 25.324 & 36.861 & 46.837 & 56.796 & 62.948 \\
\hline
\end{tabular}

Extraction method: principal component analysis. Rotation method: varimax with Kaiser normalization. ${ }^{\text {a }}$.Rotation converged in 6 iterations.

Table 3. Comparison of quality of life scores (domains and overall) by self-perceived health status: Student's $t$ test, probability values, and effect size $d$.

\begin{tabular}{|c|c|c|c|c|c|c|c|c|}
\hline QOL Domain & Health status & $\mathrm{N}$ & Mean & SD & $t$ & $d f$ & $p$ & $d$ \\
\hline \multirow{2}{*}{ Sensory Abilities } & Unhealthy & 134 & 15.13 & 3.11 & 2.15 & 225 & 0.033 & $0.29^{* *}$ \\
\hline & Healthy & 93 & 16.06 & 3.38 & & & & \\
\hline \multirow{2}{*}{ Autonomy } & Unhealthy & 134 & 16.07 & 2.80 & 1.51 & 225 & 0.132 & $0.20^{*}$ \\
\hline & Healthy & 93 & 16.63 & 2.67 & & & & \\
\hline \multirow{2}{*}{ Past/Present/Future Activities } & Unhealthy & 134 & 15.92 & 3.18 & 3.10 & 225 & 0.003 & $0.41^{* *}$ \\
\hline & Healthy & 93 & 17.10 & 2.52 & & & & \\
\hline \multirow{2}{*}{ Social Participation } & Unhealthy & 134 & 15.83 & 3.21 & 2.47 & 225 & 0.014 & $0.33^{* *}$ \\
\hline & Healthy & 93 & 16.83 & 2.69 & & & & \\
\hline \multirow{2}{*}{ Death And Dying } & Unhealthy & 134 & 15.34 & 4.52 & 1.15 & 225 & 0.253 & $0.15^{*}$ \\
\hline & Healthy & 93 & 16.02 & 4.29 & & & & \\
\hline \multirow{2}{*}{ Intimacy } & Unhealthy & 134 & 15.48 & 3.68 & 1.08 & 225 & 0.280 & $0.14^{*}$ \\
\hline & Healthy & 93 & 16.03 & 3.94 & & & & \\
\hline \multirow{2}{*}{ Total Score QoL } & Unhealthy & 134 & 93.77 & 14.11 & 2.70 & 225 & 0.007 & $0.36^{* *}$ \\
\hline & Healthy & 93 & 98.68 & 12.52 & & & & \\
\hline
\end{tabular}

Note: Sum of $\mathrm{N}$ in each domain does not equal 285 (total sample) due to missing data, ${ }^{*}$ Small effect size, ${ }^{* *}$ Medium effect size. 
Table 4. Comparison of quality of life scores (domains and overall) by educational level: ANOVA and probability values.

\begin{tabular}{|c|c|c|c|c|c|c|}
\hline QOL Domain & Educational level & $\mathrm{N}$ & Mean & SD & $\mathrm{F}_{(3,280)}$ & $p$ \\
\hline \multirow{4}{*}{ Sensory Abilities } & Illiterate & 22 & 13.09 & 3.12 & 6.220 & $<0.0001$ \\
\hline & Elementary school & 127 & 15.00 & 3.57 & & \\
\hline & Middle school & 69 & 15.48 & 3.24 & & \\
\hline & High school and College & 66 & 16.44 & 2.98 & & \\
\hline \multirow{4}{*}{ Autonomy } & Illiterate & 22 & 14.86 & 2.80 & 5.409 & $<0.001$ \\
\hline & Elementary school & 127 & 15.74 & 2.94 & & \\
\hline & Middle school & 69 & 16.72 & 2.36 & & \\
\hline & High school and College & 66 & 16.88 & 2.37 & & \\
\hline \multirow{4}{*}{ Past/Present/Future Activities } & Illiterate & 22 & 14.09 & 4.42 & 5.036 & $<0.002$ \\
\hline & Elementary school & 127 & 16.02 & 3.08 & & \\
\hline & Middle school & 69 & 16.68 & 2.92 & & \\
\hline & High school and College & 66 & 16.76 & 2.45 & & \\
\hline \multirow{4}{*}{ Social Participation } & Illiterate & 22 & 14.82 & 3.72 & 1.290 & $>0.278$ \\
\hline & Elementary school & 127 & 15.83 & 3.09 & & \\
\hline & Middle school & 69 & 16.17 & 2.86 & & \\
\hline & High school and College & 66 & 16.18 & 3.06 & & \\
\hline \multirow{4}{*}{ Death And Dying } & Illiterate & 22 & 13.09 & 5.14 & 3.636 & $<0.013$ \\
\hline & Elementary school & 127 & 15.20 & 4.61 & & \\
\hline & Middle school & 69 & 15.57 & 4.38 & & \\
\hline & High school and College & 66 & 16.53 & 3.52 & & \\
\hline \multirow{4}{*}{ Intimacy } & Illiterate & 22 & 13.86 & 4.17 & 5.290 & $<0.001$ \\
\hline & Elementary school & 127 & 15.32 & 3.57 & & \\
\hline & Middle school & 69 & 16.88 & 3.09 & & \\
\hline & High school and College & 66 & 16.17 & 3.82 & & \\
\hline \multirow{4}{*}{ Total Score Quality of Life } & Illiterate & 22 & 83.81 & 16.60 & 9.015 & $<0.0001$ \\
\hline & Elementary school & 127 & 93.11 & 14.44 & & \\
\hline & Middle school & 69 & 97.51 & 11.28 & & \\
\hline & High school and College & 66 & 98.95 & 10.81 & & \\
\hline
\end{tabular}

Note: Sum of $\mathrm{N}$ in each domain does not equal 285 (total sample) due to missing data.

Table 5. Comparison of quality of life scores (domains and overall) by gender: Student's $t$ test, probability values and effect size $d$.

\begin{tabular}{|c|c|c|c|c|c|c|c|c|}
\hline QoL Domain & Health Status & $\mathrm{N}$ & Mean & $\mathrm{SD}$ & $t$ & $d f$ & $p$ & $d$ \\
\hline \multirow{2}{*}{ Sensory Abilities } & Female & 193 & 15.55 & 3.27 & 1.70 & 283 & 0.091 & $0.20^{*}$ \\
\hline & Male & 92 & 14.81 & 3.68 & & & & \\
\hline \multirow{2}{*}{ Autonomy } & Female & 193 & 16.31 & 2.73 & 1.20 & 283 & 0.232 & $0.14^{*}$ \\
\hline & Male & 92 & 15.89 & 2.72 & & & & \\
\hline \multirow{2}{*}{ Past/Present/Future Activities } & Female & 193 & 16.39 & 3.01 & 1.38 & 283 & 0.168 & $0.16^{*}$ \\
\hline & Male & 92 & 15.85 & 3.27 & & & & \\
\hline \multirow{2}{*}{ Social Participation } & Female & 193 & 16.32 & 2.75 & 2.92 & 283 & 0.004 & $0.35^{* *}$ \\
\hline & Male & 92 & 15.10 & 3.57 & & & & \\
\hline \multirow{2}{*}{ Death And Dying } & Female & 193 & 15.03 & 4.51 & 2.32 & 283 & 0.021 & $0.28^{* *}$ \\
\hline & Male & 92 & 16.32 & 4.11 & & & & \\
\hline \multirow{2}{*}{ Intimacy } & Female & 193 & 15.99 & 3.71 & 1.32 & 283 & 0.188 & $0.16^{*}$ \\
\hline & Male & 92 & 15.38 & 3.50 & & & & \\
\hline \multirow{2}{*}{ Total Score QoL } & Female & 193 & 95.59 & 13.81 & 1.29 & 283 & 0.197 & $0.15^{*}$ \\
\hline & Male & 92 & 93.35 & 13.36 & & & & \\
\hline
\end{tabular}

*Small effect size; ${ }^{* *}$ Medium effect size. 
WHOQOL-OLD (including a confirmatory factor analysis with rotation) is required before its factor structure can be confirmed.

The Mexican Spanish version of the WHOQOL-OLD module showed acceptable correlations with the DQOL, BDI, and GDS, this being consistent with the literature [21]. All these correlations between the DQOL, BDI, and GDS and scores on the six domains (and overall) of the WHOQOL-OLD were statistically significant. Positive coefficients indicated that higher quality-of-life scores for older persons assessed with the WHOQOL-OLD are associated with higher levels of quality of life in diabetic patients, as measured by the DQOL; furthermore, negative coefficients indicated that the greater the level of depressive symptoms, the poorer the overall and domain scores for quality of life, as measured by the WHOQOLOLD [22,23]. This indicates that the Mexican Spanish version of the WHOQOL-OLD has criterion validity (convergent and divergent). This version of the WHOQOL-OLD was also shown to discriminate between self-perceived healthy and unhealthy elders [2], and also on the basis of educational level [24]. This was not case, however, for gender, where the results are conflicting [25].

\section{CONCLUSION}

The WHOQOL-OLD module is a useful alternative to the WHOQOL-100 or WHOQOL-BREF for investigating the quality of life in older adults, not least as it includes relevant aspects not covered by instruments originally designed for non-elderly populations. This study has shown that the Mexican Spanish version of the WHOQOL-OLD module (comprising 24 items spread across six domains) has adequate psychometric properties. It may therefore be used to assess the quality of life in relation to different health conditions found among the elderly [26,27]. As such, it can help in considering the needs, perceptions and interests of older adults [28].

\section{ACKNOWLEDGEMENTS}

This study was supported by grant 2009SGR00822 from the Agency for Management of University and Research Grants, Government of Catalonia.

\section{REFERENCES}

[1] World Health Organization (2002) Active ageing: A policy framework. WHO, Geneva.

http://whqlibdoc.who.int/hq/2002/WHO NMH NPH 02. 8.pdf

[2] Browne, J.P., O’Boyle, C.A., McGee, H.M., Joyce, C.R., McDonald, N.J., O’Malley, K., et al. (1994) Individual quality of life in the health elderly. Quality of Life Research, 3, 235-244.

\section{http://dx.doi.org/10.1007/BF00434897}

[3] Bowling, A., Gabriel, Z., Dykes, J. Dowding, L.M., Evans, O. Fleissig, A., Banister, D. and Sutton, S. (2003) Let's ask them: A national survey of definitions of quality of life and its enhancement among people aged 65 and over. International Journal Aging and Human Development, 56, 269-306.

http://dx.doi.org/10.2190/bf8g-5j81-ytrf-6404

[4] Power, M., Quinn, K., Schmidt, S. and WHOQOL-OLD Group (2005) Development of the WHOQOL-OLD module. Quality of Life Research, 14, 2197-2214. http://dx.doi.org/10.1007/s11136-005-7380-9

[5] The World Health Organization (1998) Quality of life assessment (WHOQOL): Development and general psychometric properties. Social Science and Medicine, 12, 1569-1585. http://dx.doi.org/10.1016/S0277-9536(98)00009-4

[6] World Health Organization (1996) WHOQOL-BREF. introduction, administration, scoring and generic version of the assessment. field trial version. Program on mental health. WHO, Geneva.

http://www.who.int/mental health/media/en/76.pdf

[7] Skevington, S.M., Lotfy, M. and O'Connell, K.A. (2004) The World Health Organization's WHOQOL-BREF quality of life assessment: Psychometric properties and results of the international field trial. A report from the WHOQOL group. Quality of Life Research, 13, 299-310. http://dx.doi.org/10.1023/B:QURE.0000018486.91360.00

[8] Lucas-Carrasco, R., Laidlaw, K. and Power, M. (2011) Suitability of the WHOQOL-BREF and WHOQOL-OLD for Spanish older adults. Aging \& Mental Health, 15, 595-604

http://dx.doi.org/10.1080/13607863.2010.548054

[9] Beck, A.T., Ward, C.H., Mendelson, M., Mock, J. and Erbaugh, J. (1961) An inventory for measuring depresssion. Archives of General Psychiatry, 4, 561-571. http://dx.doi.org/10.1001/archpsyc.1961.0171012003100 4

[10] González-Celis, A.L. (2009) Composición factorial del inventario de depresión de Beck en ancianos mexicanos. Journal of Behavior, Health \& Social Issues, 1, 15-28. http://www.redalyc.org/articulo.oa?id=282221718002\#

[11] Yesavage, J.A., Brink, T.L., Rose, T.L., Lum, O., Huang, V., Adey, M. and Leiver, V.O. (1983) Development and validation of a geriatric depression screening scale: A preliminary report. Journal of Psychiatric Research, 18, 37-49. http://dx.doi:10.1016/0022-3956(82)90033-4

[12] González-Celis, A.L. and Sánchez-Sosa, J.J. (2003) Efectos de un programa cognitivo-conductual para mejorar la calidad de vida en adultos mayores. Revista Mexicana de Psicología, 20, 43-58.

[13] Jacobson, A.M., de Groot, M. and Samson, J. (1994) Quality of life in patients with Type I and Type II diabetes mellitus. Diabetes Care, 17, 167-274. http://dx.doi.org/10.2337/diacare.17.4.267

[14] Robles-García, R., Cortázar, J., Sánchez-Sosa, J.J., PáezAgraz, F. and Nicolini-Sánchez, H. (2003) Evaluación de la calidad de vida en diabetes mellitus tipo II: Propiedades psicométricas de la versión en español del 
DQOL. Psicothema, 15, 247-252. http://redalyc2.uaemex.mx/articulo.oa?id=72715215

[15] Hattori-Hara, M. (2013) Entrenamiento en competencias de afrontamiento al paciente geriátrico con diabetes mellitus y su cuidador informal. Ph.D. Thesis, National University of Mexico, Mexico City.

[16] Kaiser, H.F. (1970) A second generation little jiffy. Psychometrika, 35, 401-415. http://dx.doi.org/10.1007/BF02291817

[17] Kaiser, H.F. (1974) An index of factorial simplicity. Psychometrika, 39, 31-36. http://dx.doi.org/10.1007/BF02291575

[18] Bartlett, M.S. (1954) A note on the multiplying factors for various chi square approximations. Journal of the Royal Statistical Society, Series B, 16, 296-298.

[19] Cohen, J. (1992) A power primer. Psychological Bulletin, 112, 155-159. http://dx.doi:10.1037/0033-2909.112.1.155

[20] Catell, R.B. (1966) The screen test for number of factors, Multivariate Behavioral Research, 1, 245-276. http://dx.doi.org/10.1207/s15327906mbr0102_10

[21] Bowling, A. (2005) Measuring health. A review of quality of life measurement scales. 3rd Edition, Open University Press, Berkshire.

[22] World Health Organization (2006) WHOQOL-OLD manual. European Office, Copenhagen, WHO, Geneva.
http://library.cph.chula.ac.th/Ebooks/WHOQOL-OLD\%2 0Final\%20Manual.pdf

[23] González-Celis, A.L. and Gómez-Benito, J. (2013) Spirituality and quality of life and its effect on depression in older adults in mexico. Psychology, 4, 178-182. http://dx.doi:10.4236/psych.2013.43027

[24] Fleck, M.P., Chachamovich, E. and Trentini, C. (2006) Development and validation of the Portuguese version of the WHOQOL-OLD module, Revista de Saúde Pública, 40, 785-791. http://www.scielo.br/pdf/rsp/v40n5/07.pdf

[25] Bowling, A. (2009) The psychometric properties of the older people's quality of life questionnaire, compared with the CASP-19 and the WHOQOL-OLD. Current Gerontology and Geriatrics Research, 2009, Article ID: 298950. http://dx.doi:10.1155/2009/298950

[26] Utzolino, S., Ober, P.A., Kaffarnik, M. Fischer, A., Hopt, U.T. and Baier, P.K. (2010) Short-and long-term health implications of surgical intensive care in the elderly. Health, 2, 1405-1412.

http://dx.doi:10.4236/health.2010.212209

[27] Esbensen, B.A. and Thomsen, T. (2011) Quality of life and hope in elderly people with cancer. Open Journal of Nursing, 1, 26-32. http://dx.doi:10.4236/ojn.2011.12004

[28] Gabriel, Z. and Bowling, A. (2004) Quality of life from the perspectives of older people. Ageing and Society, 24, 675-691. http://dx.doi:10.1017/S0144686X03001582. 